\title{
Dopaminergic cell populations of the rat substantia nigra are differentially affected by essential fatty acid dietary restriction over two generations
}

\author{
Priscila Pereira Passos ${ }^{a}$, Juliana Maria Carrazone Borba ${ }^{b}$, Ana Paula Rocha-de-Melo ${ }^{\text {, }}$, \\ Rubem Carlos Araujo Guedes ${ }^{b}$, Reginaldo Pereira da Silva ${ }^{a}$, Waldenício Teixeira Melo Filho ${ }^{a}$, \\ Kátia Maria Marques Gouveia c, Daniela Maria do Amaral Ferraz Navarro ${ }^{\mathrm{d}}$, Geanne Karla Novais Santos ${ }^{\mathrm{d}}$, \\ Roseane Borner ${ }^{\mathrm{e}}$, Cristovam Wanderley Picanço-Diniz ${ }^{\mathrm{e}}$, Antonio Pereira Jr. \\ Miriam Stela Maris de Oliveira Costa ${ }^{\mathrm{g}}$, Marcelo Cairrão Araújo Rodrigues ${ }^{\mathrm{a}}$, \\ Belmira Lara da Silveira Andrade-da-Costa ${ }^{a, *}$ \\ ${ }^{a}$ Departamento de Fisiologia e Farmacologia, Centro de Ciências Biológicas, CCB, Universidade Federal de Pernambuco, Cidade Universitária, Recife, PE, Brazil \\ ${ }^{\mathrm{b}}$ Departamento de Nutrição, Centro de Ciências da Saúde, Universidade Federal de Pernambuco, Cidade Universitária, Recife, PE, Brazil \\ ' Setor de Fisiologia e Farmacologia, Universidade Federal de Alagoas, Instituto de Ciências Biológicas e da Saúde, Campus Universitário, Maceió, AL, Brazil \\ ${ }^{\mathrm{d}}$ Departamento de Química Fundamental - Centro de Ciências Exatas e da Natureza, Universidade Federal de Pernambuco, Cidade Universitária, Recife, PE, Brazil \\ e Laboratório de Investigação em Neurodegeneração e Infecção, Instituto de Ciências Biológicas, Universidade Federal do Pará, Belém, PA, Brazil \\ ${ }^{\mathrm{f}}$ Instituto do Cérebro, Universidade Federal do Rio Grande do Norte, Natal, RN, Brazil \\ ${ }^{\mathrm{g}}$ Departamento de Morfologia, Centro de Biociências, Universidade Federal do Rio Grande do Norte, Cidade Universitária, Natal, RN, Brazil
}

\section{A R T I C L E I N F O}

\section{Article history:}

Received 17 January 2012

Received in revised form 5 May 2012

Accepted 31 May 2012

Available online 9 June 2012

\section{Key words:}

Brain development

LC-PUFA

Dopaminergic system

Maternal malnutrition

DHA

Stereology

\begin{abstract}
A B S T R A C T
Essential fatty acids play a crucial role in the activity of several neurotransmission systems, especially in the monoaminergic systems involved in cognitive and motor aspects of behavior. The present study investigated whether essential fatty acid dietary restriction over two generations could differentially affect dopaminergic cell populations located in the substantia nigra rostro-dorso-medial (SNrm) or caudo-ventro-lateral (SNcv) regions which display distinct neurochemical profile and vulnerability to lesions under selected pathological conditions. Wistar rats were raised from conception on control or experimental diets containing adequate or reduced levels of linoleic and $\alpha$-linolenic fatty acids, respectively. Stereological methods were used to estimate both the number and soma size of tyrosine hydroxylase (TH)-immunoreactive neurons in the SNrm and SNcv. TH protein levels were assessed with Western blots. Long-term treatment with the experimental diet modified the fatty acid profile of midbrain phospholipids and significantly decreased TH protein levels in the ventral midbrain (3 fold), the number of TH-positive cells in the SNrm ( 20\%) and the soma size of these neurons in both SNrm ( $\sim 20 \%)$ and SNcv $(\sim 10 \%)$. The results demonstrate for the first time a differential sensitivity of two substantia nigra dopaminergic cell populations to unbalanced levels of essential fatty acids, indicating a higher vulnerability of SNrm to the harmful effects induced by docosahexaenoic acid brain deficiency. (C) 2012 Elsevier B.V. All rights reserved.
\end{abstract}

\section{Introduction}

The nervous system is predominantly composed of lipids containing saturated, monounsaturated and polyunsaturated fatty acids. It is well established that balanced dietary levels of these fatty acids are necessary for the structural, metabolic and developmental integrity of the brain (Uauy and Dangour, 2006; Innis, 2007). Long-chain polyunsaturated fatty acids (LC-PUFA) such as arachidonic acid (AA, 20:4n-6) and docosahexaenoic acid (DHA, 22:6n-3) are major components of neuronal membrane

\footnotetext{
* Corresponding author. Tel.: +55 81 21268530; fax: +55 8121268976.

E-mail addresses: belmira@gmail.com, bl@ufpe.br (B.L.d.S. Andrade-da-Costa).
}

phospholipids and are synthesized by successive desaturation and elongation of the essential fatty acids (EFA) linoleic (LA, 18:2, n-6) and $\alpha$-linolenic (LNA, 18:3, $n-3$ ) respectively, which must be provided by the diet (Schmitz and Ecker, 2008).

A growing body of evidence has indicated that several different fatty acids may act as neuroprotectors in the brain. For example, DHA has been implicated in reducing apoptosis and necrosis in different classes of neurons (Lang-Lazdunski et al., 2003; Kim et al., 2010) while AA can be a neurotrophic factor on sensory neurons (Robson et al., 2010). The saturated stearic acid (18:0) is able to protect cortical neurons against the effects of oxidative stress (Wang et al., 2007) and the monounsaturated oleic acid (18:1n9) can behave as a neurotrophic factor in primary cell cultures (Medina and Tabernero, 2002) or promote axonogenesis in the 
striatum during brain development (Polo-Hernández et al., 2010). LC-PUFA are functionally involved with several neurotransmission systems including the monoaminergic (Zimmer et al., 2000; Chalon, 2006; Vines et al., 2012) system. Decreased levels of DHA during brain development can affect serotoninergic and dopaminergic functions in cortical or subcortical regions, modifying several aspects of behavior (Levant et al., 2004; Yavin, 2006; Chalon, 2006; Kuperstein et al., 2008; Fedorova et al., 2009; Levant et al., 2010) and contributing to the etiology of some neurological diseases (McNamara and Carlson, 2006). Thus, the dietary supplementation of LC-PUFA, especially those of the $n-3$ family, has been indicated as a therapeutic strategy for a variety of these diseases (Heinrichs, 2010). In experimental models of Parkinson disease, for example, it has been shown that the dietary supplementation of DHA or fish oil may partially restore dopaminergic neurotransmission after 6-hydroxidopamine (6OHDA) - or 1-metil-4-fenil-1,2,3,6-tetrahydropyridine (MPTP)induced striatal lesions (Bousquet et al., 2008; Cansev et al., 2008). On the other hand, in a model that associated successive parity with a maternal diet containing deficient levels of $\alpha$-linolenic acid, a reduced number of $\mathrm{TH}$-immunoreactive neurons was detected in the offspring's substantia nigra pars compacta (SNpc) at postnatal day 70 (Ahmad et al., 2008). These data suggest that an adequate $n$ 3 EFA dietary supply is necessary for the survival of dopaminergic neurons, at least from the SNpc. To our knowledge, no information is available on the vulnerability of other dopaminergic cell populations located in the substantia nigra (SN).

In the SN, dopaminergic cell populations are mainly distributed in two regions: the rostro-dorso-medial region of the SNpc (SNrm), and the caudo-ventro-lateral region ( $\mathrm{SNcv}$ ) including the $\mathrm{SN}$ pars reticulata and the ventrolateral region of pars compacta. Such populations differ in their ontogeny, morphological and neurochemical features (Bayer et al., 1995; González-Hernández et al., 2004; Duke et al., 2007) and their projections to corpus striatum can be segregated into distinct functional divisions (Joel and Weiner, 2000; Prensa and Parent, 2001). They also differ on their susceptibility to degeneration in Parkinson's disease in humans (Damier et al., 1999; Duke et al., 2007) and in rodent models (Rodríguez et al., 2001). According to these previous studies, dopaminergic neurons located in the $\mathrm{SNcv}$ are relatively more vulnerable to lesions and degenerate before the others. The distinct vulnerability of these dopaminergic populations has been ascribed to differences in their neurochemical profile, particularly the expression of calcium binding proteins, (Yamada et al., 1990; Gaspar et al., 1994), availability of the glial cell line-derived neurotrophic factor (GDNF) from the striatum (Barroso-Chinea et al., 2005), levels of plasma membrane dopamine transporter (Uhl et al., 1994; González-Hernández et al., 2004), increased expression of genes encoding pro-inflammatory cytokines and decreased expression of several glutathione-related genes (Duke et al., 2007).

Considering these neurochemical differences, the present study investigated whether the dopaminergic cells of the SNcv would be more vulnerable than those from the SNrm to the effects of a diet commonly used to induce EFA deficiency, due its reduced levels of both linoleic and $\alpha$-linolenic acids and high contents of saturated fatty acids (Deuel et al., 1954; Hargrave et al., 2005; Ling et al., 2010). We also investigated whether this dietary treatment over two generations could affect the amount of the dopaminesynthesizing enzyme in the ventral midbrain.

\section{Materials and methods}

2.1. Animals and diets

Adult female Wistar rats weighing 200-250 g were fed from mating throughout pregnancy and lactation on a control or an experimental diet, both containing around $400 \mathrm{kcal} / 100 \mathrm{~g}$ and differing only in the lipid source. The composition of the diets and their fatty acids content are shown in Tables 1 and 2, respectively. The
Table 1

Diet composition (g/100 g diet).

\begin{tabular}{lcc}
\hline Ingredients & Control diet & Experimental diet \\
\hline Casein & 20.7 & 20.7 \\
Cellulose & 1.8 & 1.8 \\
Corn starch & 46.8 & 46.8 \\
Sucrose & 21.0 & 21.0 \\
Soyabean oil & 5.0 & - \\
Coconut oil & - & 5.0 \\
Vitamin mix & 0.9 & 0.9 \\
Mineral mix & 3.7 & 3.7 \\
D,L-Cystine & 0.1 & 0.1 \\
Butyl hydroxytoluene & 0.001 & 0.001 \\
kcal/100g & 399.1 & 400.5 \\
\hline
\end{tabular}

a Vitamin mixture (Rhoster Ind.Com. LTDA, SP, Brazil) containing ( $m \%$ ): folic acid (20); niacin (300); biotin (2); calcium pantothenate 160; pyridoxine (70); riboflavin (60); thiamine chloride (60); vitamin $B_{12}(0.25)$; vitamin $K_{1}$ (7.5). Additionally containing (UI\%): vitamin A 40.000; vitamin $\mathrm{D}_{3}$ 10.000; vitamin $\mathrm{E}$ (750).

b Mineral mixture (Rhoster Ind. Com. LTDA, SP, Brazil) containing ( $m \%$ ): $\mathrm{CaHPO}_{4}$ (38); $\mathrm{K}_{2} \mathrm{HPO}_{4}$ (24); $\mathrm{CaCO}_{3}$ (18.1); $\mathrm{NaF}(0.1) ; \mathrm{NaCl}$ (7.0); $\mathrm{MgO}(2.0) ; \mathrm{MgSO}_{4} 7 \mathrm{H}_{2} \mathrm{O}$ (9.0); $\mathrm{FeSO}_{4} 7 \mathrm{H}_{2} \mathrm{O}(0.7) ; \mathrm{ZnSO}_{4} \mathrm{H}_{2} \mathrm{O}(0.5) ; \mathrm{MnSO}^{+} \mathrm{H}_{2} \mathrm{O}(0.5) ; \mathrm{CuSO}_{4} 5 \mathrm{H}_{2} \mathrm{O}(0.1) ; \mathrm{Al}_{2}$ $\left(\mathrm{SO}_{4}\right)_{3} \mathrm{~K}_{2} \mathrm{SO}_{4} 24 \mathrm{H}_{2} \mathrm{O}$ (0.02); $\mathrm{Na}_{2} \mathrm{SeO}_{3} 5 \mathrm{H}_{2} \mathrm{O}$ (0.001); $\mathrm{KCl}(0.008)$.

Table 2

Fatty acid composition of the diets (\% of total fatty acids).

\begin{tabular}{|c|c|c|}
\hline Fatty acids & Control diet & Experimental diet \\
\hline 8 & 0.02 & 3.27 \\
\hline 10 & 0.03 & 3.95 \\
\hline 11 & nd & 0.07 \\
\hline 12 & 0.20 & 28.04 \\
\hline 13 & nd & 0.06 \\
\hline 14 & 0.19 & 19.56 \\
\hline 15 & 0.02 & 0.02 \\
\hline 16 & 9.27 & 11.32 \\
\hline 17 & nd & 0.02 \\
\hline 18 & 15.31 & 0.72 \\
\hline 20 & 0.33 & 0.16 \\
\hline 22 & 0.51 & 0.08 \\
\hline 23 & 0.07 & 0.02 \\
\hline 24 & 0.04 & nd \\
\hline Total saturated & 26.01 & 67.29 \\
\hline $16: 1$ & 2.72 & 0.06 \\
\hline $18: 1 n 9$ & 9.36 & 23.51 \\
\hline $20: 1$ & 0.24 & 0.16 \\
\hline Total monounsaturated & 12.32 & 23.73 \\
\hline $18: 2 n 6$ & 55.36 & 8.10 \\
\hline $18: 3 n 3$ & 6.04 & 0.49 \\
\hline $20: 2$ & 0.04 & 0.06 \\
\hline $20: 5 n 3$ & 0.03 & nd \\
\hline $22: 2 n$ & 0.05 & 0.04 \\
\hline $22: 6 n 3$ & 0.13 & 0.06 \\
\hline Total polyunsaturated & 61.65 & 8.75 \\
\hline $18: 2 n 6 / 18: 3 n 3$ & 9.17 & 16.39 \\
\hline
\end{tabular}

nd $=$ not detected.

diets were prepared according to Soares et al. (1995), submitted to transesterification according to Hartman and Lago (1973) and analyzed using gas chromatography. The control diet contained $5 \%$ of soybean oil with adequate amounts of saturated, monounsaturated, $\alpha$-linolenic and linoleic fatty acids. The experimental diet contained 5\% coconut oil with reduced levels of linoleic acid ( $\sim 7$ times reduction, corresponding to about $30 \%$ of recommended minimal dietary requirement for rodents (Bourre et al., 1990)) and $\alpha$-linolenic acid ( $\sim 12$ times reduction), and higher levels of saturated ( 2 fold) and monounsaturated ( 2.5 fold) fatty acids. The diets differed also regarding the linoleic/ $\alpha$-linolenic acids ratio which was 9:1 for the control and 16:1 for the experimental version. They were prepared at least twice a month and stored in a refrigerator at $4 \pm 2{ }^{\circ} \mathrm{C}$.

The offspring ( $n=80$ males) of both groups were the object of the present study. At parturition, litter size, total litter weight and mean birth weight of the pups was recorded. Litters were then reduced to 6 pups each, by keeping the median weighted animals (identified with distinct marks). Dams and male pups were divided into two main groups according to the nutritional condition: control (C) and experimental rats (E). After weaning, on postnatal day (P) 21 , the rat pups were 
separated and fed ad libitum the same diet as their respective mothers. They were the first generation (CF1 and EF1) and were allowed to mate at 90-110 days to provide the second generation groups (CF2 and EF2) which were analyzed at 30-42 days. In each group, animals were sampled randomly from different litters, housed three per cage in a room maintained at $22 \pm 2{ }^{\circ} \mathrm{C}$ with $67 \%$ relative air humidity and kept on a $12 \mathrm{~h}$ light/dark cycle (lights on 6:00 h). All animal procedures were carried out in accordance with the norms of the Ethics Committee for Animal Research of Federal University of Pernambuco (CEEA) which specifically approved this study (protocol \# 009428/200633), and complies with the "Principles of Laboratory Animal Care" (NIH, Bethesda, USA).

\subsection{Fatty acid determination in the midbrain and cerebral cortex}

The fatty acid profiles of midbrain and cerebral cortex phospholipids were assessed in F2 groups at 35 days of age. Pups were decapitated and the regions containing the midbrain or cerebral cortex were rapidly dissected in an ice bath. Tissues were homogenized in a $50 \mathrm{mM}$ Tris- $\mathrm{HCl}$ buffer with EGTA and centrifuged for $30 \mathrm{~min}$ at $28,000 \times \mathrm{g}$ at $4{ }^{\circ} \mathrm{C}$. Pellets were immediately resuspended in $50 \mathrm{mM}$ Tris. Total lipids of brain homogenates were extracted according to Folch et al. (1957). Phospholipids were then separated by means of a Sep-Pak procedure (Juaneda and Rocquelin, 1985) and transmethylated (Berry et al., 1965). Samples were analyzed using a Thermo Trace Ultra GC apparatus equipped with a flame ionization detector and HP-20 (carbowax 20 M) capillary column $(25 \mathrm{~m} \times 0.32 \mathrm{~mm} \times 0.3 \mu \mathrm{m})$. The column temperature was initially $40{ }^{\circ} \mathrm{C}$ for $1 \mathrm{~min}$, then increased to $150{ }^{\circ} \mathrm{C}$ by $55^{\circ} \mathrm{C} / \mathrm{min}$, and finally increased to $220^{\circ} \mathrm{C}$ by $1.7^{\circ} \mathrm{C} / \mathrm{min}$. The injector and detector temperatures were 200 and $220^{\circ} \mathrm{C}$, respectively. Nitrogen was used as the carrier gas at a flow rate of $1.0 \mathrm{ml} / \mathrm{min}$; injection was in split mode $(1: 20)$ and the injection volume was $1.0 \mu \mathrm{l}$ of sample isooctane extract. A standard fatty acid methyl ester mixture (Supelco, USA) was used to identify most of fatty acid methyl esters by their retention time. The docosapentanoic acid (DPA) of our samples was identified by using gas chromatography-mass spectrometry (GC-MS). Thus, the presence of DPA peak and its mass spectrum was compared with that obtained in the mass spectrum libraries of the equipment (Willey, Nist and Adams). Fatty acid data were expressed as \% of total peak area. Data are expressed as the mean \pm standard error of the mean (SEM). Differences between groups were analyzed by Student's $T$ test. Differences were considered significant at $P<0.05$.

\subsection{Protein extraction and Western blotting analysis}

Ventral midbrain homogenates containing samples of 6 animals per group were obtained at P35-42 from the CF2 and EF2 groups. Such samples were homogenized in freshly prepared $20 \mathrm{mM}$ Tris/ $\mathrm{HCl}$ buffer ( $\mathrm{pH} 7.4$ ) containing $10 \mathrm{mM} \mathrm{MgCl}$, $0,6 \mathrm{mM} \mathrm{CaCl} 2,0.5 \mathrm{mM}$ EGTA, $1 \mathrm{mM}$ DTT, $1 \mathrm{mM}$ phenylmethylsulfonyl fluoride (PMSF), $2 \mu \mathrm{g} / \mathrm{ml}$ leupeptin and $0.05 \%$ Triton X-100. An aliquot was taken to determine protein content. An equal volume of sample buffer $(62.5 \mathrm{mM}$ Tris/ $\mathrm{HCl}$, $\mathrm{pH} 7.4$, containing $4 \%$ SDS, $10 \%$ glycerol, $10 \%$ mercaptoethanol and $0.002 \%$ bromophenol blue) was added, and samples were boiled for approximately $3 \mathrm{~min}$. Fractioning of protein samples was achieved using $10 \%$ polyacrylamide gels containing $0.1 \%$ SDS. After separation, the protein bands were transferred from the gel onto nitrocellulose paper, as described by Towbin et al. (1979). The nitrocellulose blots were incubated with mouse anti-TH polyclonal antibody (1:500; Chemicon, Temecula, CA, USA) or mouse anti- $\beta$-actin polyclonal antibody (1:5000; Chemicon, Temecula, CA, USA) and then incubated for $3 \mathrm{~h}$ at room temperature. They were subsequently exposed to mouse secondary antibodies conjugated to horseradish peroxidase and developed with a $0.16 \%$ solution of $3-$ amino-9-ethylcarbazole in $50 \mathrm{nM}$ sodium acetate buffer ( $\mathrm{pH} \mathrm{5)}$ containing $0.05 \%$ Tween-20 and $0.03 \% \mathrm{H}_{2} \mathrm{O}_{2}$. Digital images of the blots were obtained and the integrated optical density was estimated by using Labworks software (UVP Products, CA). TH protein levels were normalized to that of the $\beta$-actin protein that was used as an internal standard.

\subsection{Immunohistochemical procedures}

Rats (seven animals per group) were anesthetized with sodium pentobarbital $(60-80 \mathrm{mg} / \mathrm{kg}$, i.p.) and perfused transcardially first with saline $(0.9 \% \mathrm{NaCl} ; 50-$ $100 \mathrm{ml}$ ) followed by $4 \%$ paraformaldeyde in $0.1 \mathrm{M}$ phosphate buffer (PB), pH 7.4 $(200 \mathrm{ml})$. Perfusion was always performed between 12:00 and 18:00, with a continuous infusion pump (Harvard equipment) through a cannula inserted into the left ventricle with a perfusion rate at $7.64 \mathrm{ml} / \mathrm{min}$. After perfusion, the brains were dissected starting from the prefrontal cortex back to the inferior limit of the brainstem (the olfactory bulb and cochleas were excluded). They were then postfixed for $2 \mathrm{~h}$ in the same fixative, rinsed in $\mathrm{PB}$ and weighed (wet weight). Subsequently, the brains were cryoprotected in solutions of $10 \%, 20 \%$ and $30 \%$ sucrose in PB.

Brain blocks were serially cut on a freezing microtome (Leitz Wetzlar) into $50 \mu \mathrm{m}$-thick sections in the parasagittal plane, throughout the latero-medial extent of each hemi-brain. All sections were collected serially in PB and arranged in six series. The atlas of Paxinos and Watson (1986) was used to delimit the cytoarchitectonic regions. The series of sections used for immunohistochemistry was first treated with $0.01 \mathrm{M}$ citrate buffer, $\mathrm{pH} 6.0$, at $60{ }^{\circ} \mathrm{C}$ for $2 \mathrm{~h}$. Thereafter, freefloating sections were rinsed in $\mathrm{PB}$ several times and incubated with rabbit anti-TH polyclonal antibody (Chemicon, USA) diluted $1: 500$ in PB containing $0.3 \%$ Triton X100 (PBX) and $1 \%$ normal goat serum (NGS) for $24 \mathrm{~h}$ at $4{ }^{\circ} \mathrm{C}$. Sections were then incubated for $1.5 \mathrm{~h}$ in secondary antiserum (biotinylated goat anti-rabbit IgG; Vector Labs, Burlingame, CA) diluted 1:200 in PBX, and processed for immunoperoxidase staining using the avidin biotin peroxidase complex (Standard ABC kit, Vector Labs). The binding of antibodies was revealed by the addition of diaminobenzidine tetrahydrochloride $0.05 \%$ (Sigma) and $0.01 \% \mathrm{H}_{2} \mathrm{O}_{2}$ in $\mathrm{PB}$, for $10 \mathrm{~min}$. Subsequently, the free-floating sections were rinsed in $\mathrm{PB}$ and mounted on gelatin-coated slides. These procedures were carried out simultaneously in brain sections from both control and experimental animals. For the control of the staining specificity, some sections were subjected to an immunohistochemical procedure, omitting the primary antibody.

\subsection{Stereological and morphometric analysis}

Total estimates of the number of dopaminergic neurons in the SNrm and SNcv were obtained from seven brains per group processed for TH immunohistochemistry. In order to encompass the full latero-medial extent of the SN in the left side of the brain, six sections from a 1:6 series were analyzed for each brain. Optical fractionator sampling was carried out using a Nikon Eclipse 80 microscope equipped with an advanced scientific instrumentation motorized stage input into a high resolution plasma monitor and linked to a MBF CX 9000 color digital video camera. Sampling used to count stained cells was implemented using Stereoinvestigator software (MicroBrightField Inc.; Williston, USA). Areas of interest containing dopaminergic populations were outlined with reference to an atlas of the rat brain (Paxinos and Watson, 1986). Boundaries separating the SNrm and SNcv were identified based on the location of anatomical landmarks and digitized directly from each section using a $4 \times$ objective. Every sixth section containing the regions of interest was selected from a random initial sort to ensure random overall sampling. The stereology was performed at high magnification with an $100 \times / 1.4$ aperture oil immersion lens which allows for clear visualization of the nucleus and precise definition of the cell walls.

Pilot studies were carried out to determine suitable counting frame and sampling grid dimensions prior to counting in each region of $\mathrm{SN}$ to allow approximately 25-30 and 70-85 sampling sites per section for SNrm and SNcv respectively. The level of acceptable error in the stereological estimations was defined by the ratio between the intrinsic error introduced by the methodology and the coefficient of the variation. The coefficient of error (CE) expresses the accuracy of the cell number estimates and a value of $\mathrm{CE} \leq 0.10$ was deemed appropriate for the present study, because variance introduced by the estimation procedure contributes little to the observed group variance (Glaser and Wilson, 1998). The optical fractionator method determines the number of cells by multiplying the number of objects identified inside each counting box by the values of three ratios: (a) the ratio between the number of sections sampled and the total number of sections (section sampling fraction, ssf); (b) the ratio of the counting box and the area of the grid (area sampling fraction, asf); and (c) the ratio between the height of the counting frame and the section thickness after histological procedures (thickness sampling fraction, tsf) (West, 2002). The total number of TH-positive cells was obtained using the following equation: $N=\sum Q \times(1 / \mathrm{ssf}) \times(1 / \mathrm{asf}) \times(1 /$ tsf) where $N$ is the total number of cells and $\sum Q$ is the number of counted objects (West, 2002). The experimental parameters adopted for the stereological analysis are shown in Table 3.

For the soma size the area measurements were carried out using the Neurolucida System for Neuroanatomical Analysis (MicroBrightField Inc.; Williston, USA). A systematic random sampling of cells was implemented using high magnification images with $100 \times / 1.3$ aperture oil immersion lenses in those cases in which the cell nucleus could be clearly identified. This analysis was carried out in six animals per group. Ten cells per section were analyzed in each region, corresponding to a total of 60 cells per region. Thus, a total of 360 cells were analyzed per group in the SNrm or SNcv. The nonparametric Kruskal-Wallis ANOVA Ranks test, $\alpha<0.05$, was used to analyze the effects of diets and regions on the measures of neuronal soma size and the Dunn's test, $\alpha<0.05$ was further utilized to determine post hoc comparison among groups and regions using GraphPad Prism version 5.00 for Windows, GraphPad Software, San Diego, CA, USA, www.graphpad.com.

Fig. 1A illustrates the regional borders of SNrm and SNcv used for stereological quantification and Fig. 1B shows a random sampling of cells for analysis of soma area in six parasagittal sections of two representative control animals.

\section{Results}

\subsection{Body and brain weights}

Body and brain weights at 30-42 days were significantly smaller in the EF2 group as compared to the control. Nevertheless, the brain weight/body weight ratio did not differ between the groups (Table 4 ). 
Table 3

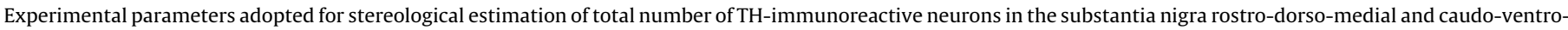
lateral of control (CF2) and experimental (EF2) groups.

\begin{tabular}{|c|c|c|c|c|c|c|c|c|}
\hline $\begin{array}{l}\text { Regions and } \\
\text { subjects }\end{array}$ & $\begin{array}{l}\alpha \text { (frame) } \\
\left(\mu \mathrm{m}^{2}\right)\end{array}$ & $\begin{array}{l}A(x, y \text { step }) \\
\left(\mu \mathrm{m}^{2}\right)\end{array}$ & asf & tsf & ssf & $\begin{array}{l}\text { Number of } \\
\text { counting frames }\end{array}$ & $\begin{array}{l}\text { Number of } \\
\text { sections }\end{array}$ & $\begin{array}{l}\text { Total markers } \\
\text { counted }\end{array}$ \\
\hline \multicolumn{9}{|l|}{ SNrm } \\
\hline \multicolumn{9}{|l|}{ CF2 group } \\
\hline $\mathrm{S} 1$ & $120 \times 120$ & $120 \times 120$ & 1 & 0.62 & $1 / 6$ & 152 & 6 & 1018 \\
\hline $\mathrm{S} 2$ & $120 \times 120$ & $120 \times 120$ & 1 & 0.68 & $1 / 6$ & 147 & 6 & 980 \\
\hline S3 & $120 \times 120$ & $120 \times 120$ & 1 & 0.71 & $1 / 6$ & 192 & 6 & 956 \\
\hline S4 & $120 \times 120$ & $120 \times 120$ & 1 & 0.69 & $1 / 6$ & 174 & 6 & 972 \\
\hline S5 & $120 \times 120$ & $120 \times 120$ & 1 & 0.52 & $1 / 6$ & 150 & 6 & 1146 \\
\hline S6 & $120 \times 120$ & $120 \times 120$ & 1 & 0.67 & $1 / 6$ & 151 & 6 & 972 \\
\hline S7 & $120 \times 120$ & $120 \times 120$ & 1 & 0.61 & $1 / 6$ & 178 & 6 & 1118 \\
\hline \multicolumn{9}{|l|}{ EF2 group } \\
\hline $\mathrm{C} 1$ & $120 \times 120$ & $120 \times 120$ & 1 & 0.70 & $1 / 6$ & 184 & 6 & 841 \\
\hline $\mathrm{C} 2$ & $120 \times 120$ & $120 \times 120$ & 1 & 0.67 & $1 / 6$ & 175 & 6 & 797 \\
\hline C3 & $120 \times 120$ & $120 \times 120$ & 1 & 0.68 & $1 / 6$ & 153 & 6 & 867 \\
\hline $\mathrm{C} 4$ & $120 \times 120$ & $120 \times 120$ & 1 & 0.67 & $1 / 6$ & 159 & 6 & 908 \\
\hline $\mathrm{C} 5$ & $120 \times 120$ & $120 \times 120$ & 1 & 0.71 & $1 / 6$ & 163 & 6 & 997 \\
\hline C6 & $120 \times 120$ & $120 \times 120$ & 1 & 0.68 & $1 / 6$ & 148 & 6 & 1100 \\
\hline $\mathrm{C} 7$ & $120 \times 120$ & $120 \times 120$ & 1 & 0.62 & $1 / 6$ & 132 & 6 & 730 \\
\hline \multicolumn{9}{|l|}{ SNCV } \\
\hline \multicolumn{9}{|l|}{$\mathrm{CF} 2$ group } \\
\hline $\mathrm{S} 1$ & $120 \times 120$ & $120 \times 120$ & 1 & 0.60 & $1 / 6$ & 437 & 6 & 649 \\
\hline $\mathrm{S} 2$ & $120 \times 120$ & $120 \times 120$ & 1 & 0.70 & $1 / 6$ & 487 & 6 & 458 \\
\hline S3 & $120 \times 120$ & $120 \times 120$ & 1 & 0.60 & $1 / 6$ & 425 & 6 & 363 \\
\hline S4 & $120 \times 120$ & $120 \times 120$ & 1 & 0.83 & $1 / 6$ & 502 & 6 & 370 \\
\hline S5 & $120 \times 120$ & $120 \times 120$ & 1 & 0.76 & $1 / 6$ & 471 & 6 & 675 \\
\hline S6 & $120 \times 120$ & $120 \times 120$ & 1 & 0.68 & $1 / 6$ & 402 & 6 & 525 \\
\hline S7 & $120 \times 120$ & $120 \times 120$ & 1 & 0.65 & $1 / 6$ & 480 & 6 & 595 \\
\hline \multicolumn{9}{|l|}{ EF2 group } \\
\hline $\mathrm{C} 1$ & $120 \times 120$ & $120 \times 120$ & 1 & 0.55 & $1 / 6$ & 421 & 6 & 361 \\
\hline $\mathrm{C} 2$ & $120 \times 120$ & $120 \times 120$ & 1 & 0.59 & $1 / 6$ & 452 & 6 & 313 \\
\hline $\mathrm{C} 3$ & $120 \times 120$ & $120 \times 120$ & 1 & 0.76 & $1 / 6$ & 404 & 6 & 233 \\
\hline $\mathrm{C} 4$ & $120 \times 120$ & $120 \times 120$ & 1 & 0.63 & $1 / 6$ & 429 & 6 & 290 \\
\hline $\mathrm{C} 5$ & $120 \times 120$ & $120 \times 120$ & 1 & 0.69 & $1 / 6$ & 455 & 6 & 419 \\
\hline C6 & $120 \times 120$ & $120 \times 120$ & 1 & 0.82 & $1 / 6$ & 401 & 6 & 483 \\
\hline C7 & $120 \times 120$ & $120 \times 120$ & 1 & 0.88 & $1 / 6$ & 451 & 6 & 385 \\
\hline
\end{tabular}

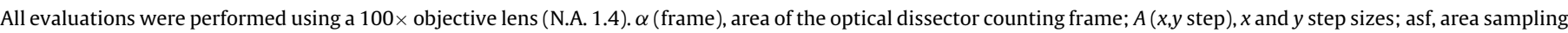

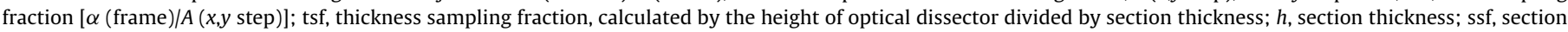
sampling fraction.

\subsection{Midbrain and cerebral cortex phospholipid fatty acid composition}

Table 5 shows the mean percentage of midbrain fatty acid in rats raised on either the control or experimental diets. As can be observed, rats from the EF2 group exhibited a 50\% less DHA

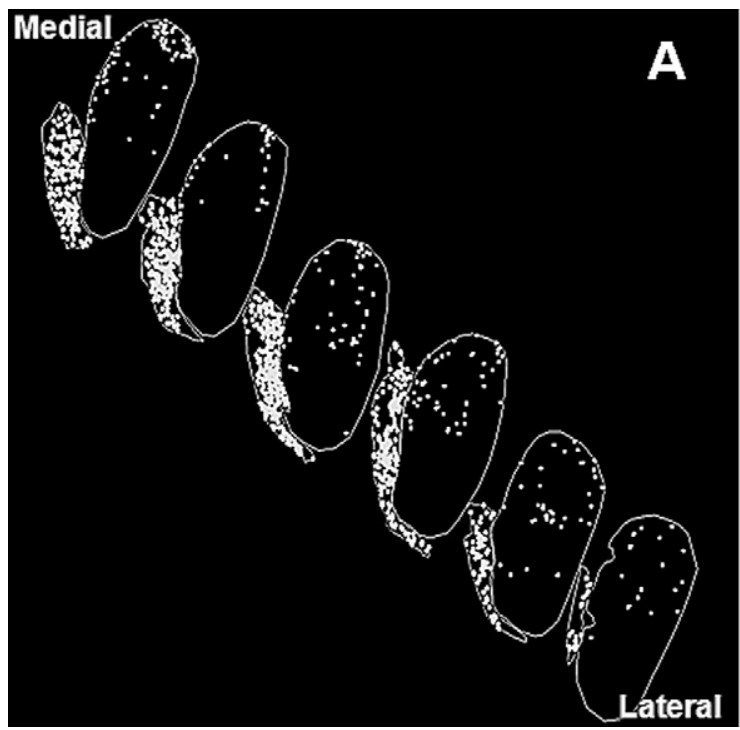

(22:6n-3) levels accompanied by a compensatory increase ( $\sim 6$ fold) in the DPA (22:5n-6) when compared to the control group. On the other hand, the values for AA (20:4n-6) did not differ between the groups. With respect to saturated and monounsaturated fatty acids, higher levels of palmitic (16:0), stearic (18:0), palmitoleic

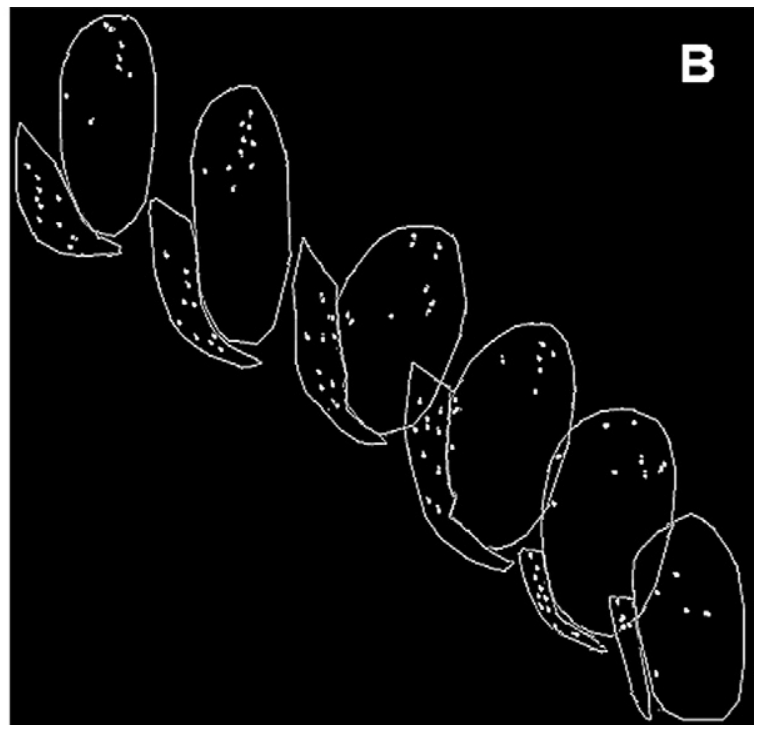

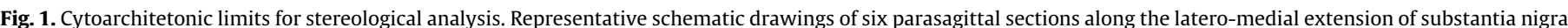

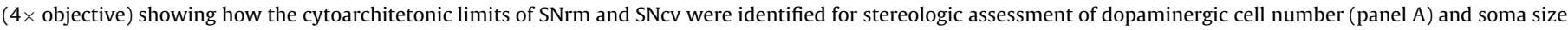
(panel B). Dots represent TH positive neurons counted in each section (panel A) and ten of these neurons randomly selected per region and per section (panel B). 
Table 4

Body and brain weights.

\begin{tabular}{|c|c|c|c|}
\hline Groups & Body weight & Brain weight & Brain weight/body weight ratio \\
\hline $\mathrm{CF} 2$ & $85.67 \pm 14.12 \mathrm{~g}(n=18)$ & $1.68 \pm 0.06 \mathrm{~g}(n=12)$ & $0.0158 \pm 0.003 \mathrm{~g}(n=12)$ \\
\hline EF2 & $74.41 \pm 5.90 \mathrm{~g}^{*}(n=13)$ & $1.56 \pm 0.11 \mathrm{~g}^{*}(n=8)$ & $0.0148 \pm 0.002 \mathrm{~g}(n=8)$ \\
\hline
\end{tabular}

Values are expressed as mean \pm SD. $n$, number of animals; unpaired Student's $T$-test. $P<0.05$.

Table 5

Fatty acid composition (\% of total) in midbrain membrane phospholipids of F2 generation groups raised on control or experimental diets.

\begin{tabular}{lcc}
\hline \multirow{2}{*}{ Fatty acid } & \multicolumn{2}{l}{ Midbrain } \\
\cline { 2 - 3 } & \multicolumn{1}{c}{ Control diet } & Experimental diet \\
\hline C16 & $16.51 \pm 1.90$ & $24.09 \pm 0.27^{*}$ \\
C16:1 & $0.64 \pm 0.04$ & $0.85 \pm 0.03$ \\
C17 & $0.16 \pm 0.00$ & $0.20 \pm 0.02$ \\
C18 & $24.88 \pm 0.67$ & $29.09 \pm 0.37^{*}$ \\
C18:1n9 & $16.38 \pm 0.25$ & $19.21 \pm 0.21^{*}$ \\
C18:2n6t & $0.74 \pm 0.17$ & $0.65 \pm 0.22$ \\
C20:1 & $0.62 \pm 0.10$ & $0.60 \pm 0.05$ \\
C20:4n6 (AA) & $13.74 \pm 0.83$ & $14.93 \pm 0.48$ \\
C23 & $3.98 \pm 0.20$ & $3.52 \pm 0.19$ \\
C22:5n6 & $1.49 \pm 0.11$ & $9.39 \pm 0.31^{* *}$ \\
C22:6n3 (DHA) & $19.70 \pm 0.69$ & $8.70 \pm 0.73^{* *}$ \\
\hline
\end{tabular}

Values are expressed as means \pm SD. nd $=$ not detected. $P<0.01$.

$P<0.001$.

(16:1) and oleic (18:1n9) acids (2-tail $T$-test, $P<0.01)$ were detected in the EF2 group midbrain phospholipids in comparison to the control. Similar results were obtained in the cerebral cortex phospholipids where DHA levels in the EF2 group $(9.99 \pm 0.41 \%)$ were significantly lesser than that observed in the control $(21.22 \pm 0.41 \%)$. Increased levels of DPA were detected in the cerebral cortex of EF2 group $(9.6 \pm 0.26 \%)$ when compared to control $(1.54 \pm 0.06 \%)$ but no difference between the groups was detected in the AA levels $(14.79 \pm 0.35 \%$ and $14.93 \pm 0.43 \%$ in the control and EF2 groups respectively).

\subsection{Characterization and stereological analysis of SN dopaminergic cell populations}

Fig. 2A and D depicts low magnification images of representative parasagittal sections through the SN in animals of CF2 and EF2 groups, respectively. The $\mathrm{TH}$-immunoreactivity pattern shows the distribution of dopaminergic neurons in the SNrm and SNcv as well as in the retrorubral field (RRF). Fig. 2B, C, E, and F shows higher magnification images of SNrm (B and E) and $\mathrm{SNcv}$ (C and F) of both groups. As can be observed, neurons located in the SNrm or SNcv differ with respect to morphological features and soma size. THimmunoreactivity is less intense in the EF2 animal when compared to the control.

Stereological analysis of TH-positive cells in the $\mathrm{SN}$ is presented in Table 6 which shows individual and average values for the seven subjects per group, including the planimetric volumes of SNrm or SNcv, coefficient of errors and biological variability. On average, the numbers of TH-immunoreactive cells in the SNrm and in the SNcv of the control group were respectively $9715 \pm 1835$ and $4570 \pm 1510$. Combining the data of these two regions, a total of $14,285 \pm 2995$ dopaminergic neurons in the left SN were estimated. A comparative analysis between the two groups showed that in the SNrm the number of TH-immunoreactive cells in rats fed the deficient diet was $20 \%$ lower than in those fed the control

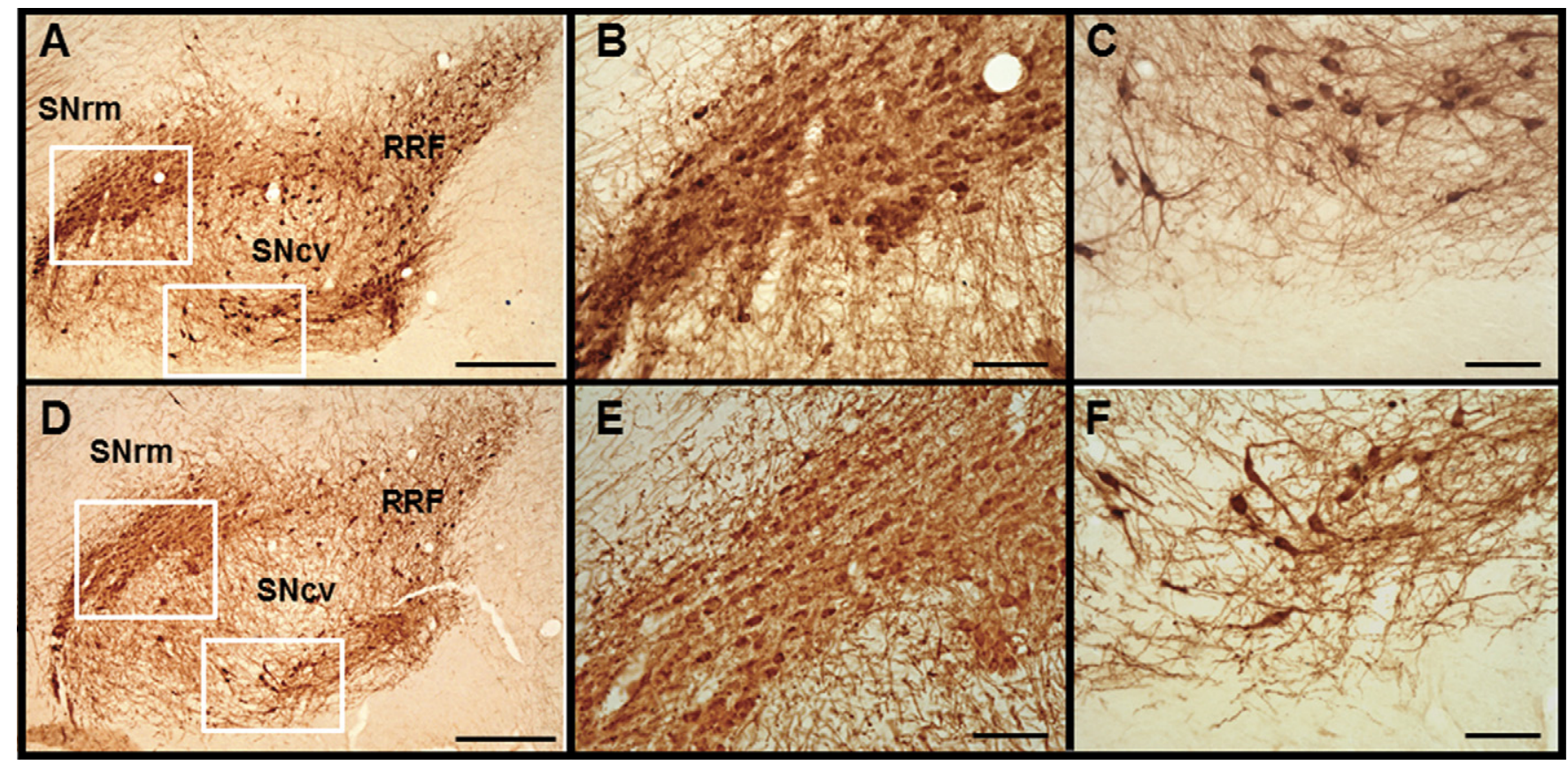

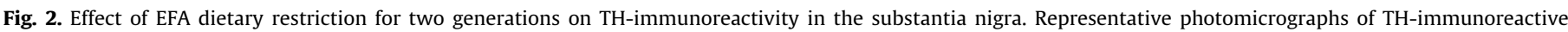

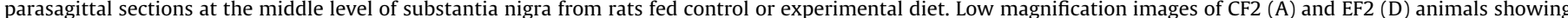

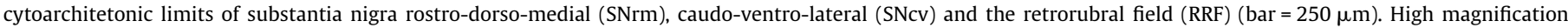
images of (A) and (D) show dopaminergic cell features in the SNrm and SNcv from CF2 (B and C) and EF2 (E and F) animals (bar $=30 \mu \mathrm{m})$. 
Table 6

Estimated individual unilateral planimetric volumes of SNcv and SNrm and correspondent unilateral number of their respective dopaminergic cells.

\begin{tabular}{|c|c|c|c|c|c|c|c|c|c|c|c|}
\hline \multirow[t]{2}{*}{ Subjects } & \multicolumn{5}{|l|}{ SNcV } & \multicolumn{5}{|l|}{ SNrm } & \multirow{2}{*}{$\begin{array}{l}\text { SNcv }+ \text { SNrm } \\
\text { Total cells }\end{array}$} \\
\hline & Thickness & Volume $\left(\mathrm{mm}^{3}\right)$ & $\mathrm{CE}$ & Total cells & $\mathrm{CE}$ & Thickness & Volume $\left(\mathrm{mm}^{3}\right)$ & $\mathrm{CE}$ & Total cells & $\mathrm{CE}$ & \\
\hline \multicolumn{12}{|l|}{ CF2 group } \\
\hline S1 & 13.4 & 1.48 & 0.04 & 6.720 & 0.08 & 12.8 & 0.33 & 0.06 & 9.884 & 0.07 & 16.604 \\
\hline $\mathrm{S} 2$ & 11.3 & 1.19 & 0.06 & 3.865 & 0.08 & 11.6 & 0.30 & 0.06 & 8.579 & 0.07 & 12.444 \\
\hline S3 & 13.2 & 1.07 & 0.05 & 3.617 & 0.08 & 11.2 & 0.24 & 0.11 & 8.180 & 0.07 & 11.797 \\
\hline S4 & 9.6 & 1.39 & 0.07 & 2.149 & 0.10 & 11.6 & 0.24 & 0.09 & 8.427 & 0.07 & 10.576 \\
\hline S5 & 10.4 & 1.29 & 0.06 & 5.369 & 0.08 & 15.1 & 0.27 & 0.13 & 13.138 & 0.07 & 18.507 \\
\hline S6 & 11.6 & 1.19 & 0.06 & 4.618 & 0.08 & 11.8 & 0.19 & 0.05 & 8.656 & 0.07 & 13.274 \\
\hline S7 & 12.4 & 1.32 & 0.05 & 5.650 & 0.07 & 12.9 & 0.36 & 0.05 & 11.141 & 0.06 & 16.791 \\
\hline Mean & 11.7 & 1.28 & 0.055 & 4.570 & 0.081 & 12.4 & 0.276 & 0.060 & 9.715 & 0.068 & 14.285 \\
\hline SD & 1.4 & 0.14 & 0.009 & 1.510 & 0.009 & 1.3 & 0.058 & 0.031 & 1.835 & 0.004 & 2.995 \\
\hline $\mathrm{CV}^{2}$ & & 0.012 & & 0.109 & & & 0.044 & & 0.035 & & \\
\hline$C E^{2}$ & & 0.003 & & 0.006 & & & 0.006 & & 0.005 & & \\
\hline $\mathrm{CE}^{2} / \mathrm{CV}^{2}$ & & 0.259 & & 0.060 & & & 0.138 & & 0.129 & & \\
\hline CVB & & 0.010 & & 0.102 & & & 0.038 & & 0.031 & & \\
\hline $\mathrm{CVB}^{2}\left(\% \mathrm{CV}^{2}\right)$ & & 74.02 & & 93.98 & & & 86.36 & & 87.07 & & \\
\hline \multicolumn{12}{|l|}{ EF2 group } \\
\hline $\mathrm{C} 1$ & 14.3 & 1.57 & 0.06 & 4433 & 0.09 & 11.4 & 0.33 & 0.08 & 7237 & 0.06 & 11,670 \\
\hline $\mathrm{C} 2$ & 13.4 & 1.62 & 0.04 & 3035 & 0.09 & 11.9 & 0.32 & 0.09 & 7122 & 0.07 & 10,157 \\
\hline $\mathrm{C} 3$ & 10.5 & 1.39 & 0.06 & 2304 & 0.09 & 11.6 & 0.31 & 0.07 & 7543 & 0.07 & 9847 \\
\hline $\mathrm{C} 4$ & 12.7 & 1.32 & 0.07 & 4143 & 0.10 & 11.9 & 0.35 & 0.07 & 8125 & 0.07 & 12,268 \\
\hline C5 & 11.6 & 1.44 & 0.06 & 4253 & 0.10 & 11.2 & 0.32 & 0.10 & 8416 & 0.07 & 12,669 \\
\hline $\mathrm{C} 6$ & 9.7 & 1.08 & 0.04 & 1722 & 0.09 & 11.7 & 0.33 & 0.08 & 9687 & 0.07 & 11,409 \\
\hline $\mathrm{C7}$ & 9.1 & 1.62 & 0.08 & 2670 & 0.09 & 11.2 & 0.42 & 0.07 & 6158 & 0.07 & 8828 \\
\hline Mean & 11.6 & 1.28 & 0.058 & 3222 & 0.093 & 11.6 & 0.344 & 0.080 & $7755^{\#}$ & 0.068 & $10,978^{\#}$ \\
\hline SD & 1.9 & 0.14 & 0.015 & 1065 & 0.005 & 0.3 & 0.039 & 0.011 & 1123 & 0.004 & 1400 \\
\hline $\mathrm{CV}^{2}$ & & 0.009 & & 0.109 & & & & 0.113 & 0.021 & & \\
\hline $\mathrm{CE}^{2}$ & & 0.003 & & 0.008 & & & & 0.006 & 0.005 & & \\
\hline $\mathrm{CE}^{2} / \mathrm{CV}^{2}$ & & 0.354 & & 0.079 & & & & 0.056 & 0.220 & & \\
\hline $\mathrm{CVB}^{2}$ & & 0.006 & & 0.100 & & & & 0.106 & 0.016 & & \\
\hline $\mathrm{CVB}^{2}\left(\% \mathrm{CV}^{2}\right)$ & & 64.63 & & 92.11 & & & & 94.33 & 77.99 & & \\
\hline
\end{tabular}

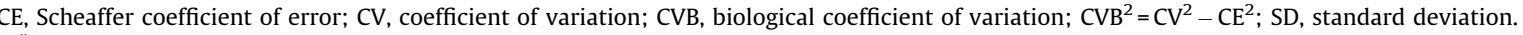

\# $P<0.05$ versus control.

$\operatorname{diet}(7755 \pm 1123 ; 2$-tail $T$-test, $P=0.036)$. On the other hand, in the SNcv no significant difference between the groups was detected (EF2 group $=3222 \pm 1065 ; \quad 2$-tail $T$-test, $P=0.116)$. A total of $10,978 \pm 1400$ dopaminergic neurons was estimated in the left SN of the EF2 group which is $23 \%$ lower than the value estimated in the respective control ( 2 -tail $T$-test, $P=0.028$ ).

\subsection{Effects of the dietary treatment on dopaminergic cell soma size}

In both the control and EF2 groups, the soma area of these cells ranged from 86 to $496 \mu \mathrm{m}^{2}$ in the SNrm and from 110 to $527 \mu \mathrm{m}^{2}$ in the SNcv. The soma size frequencies of these neurons were found to be distinguishable from a normal distribution (Shapiro Wilk's $W$ test, $P<0.05)$ in both regions within each group. Fig. $3 \mathrm{~A}$ and $\mathrm{B}$ illustrates comparative frequency histograms of soma size in the SNrm and SNcv of both groups. The predominant classes of soma size differed significantly between these two regions in each group $(P<0.01)$. The long term dietary treatment with the experimental diet resulted in lower dopaminergic cell size both in the SNrm (median $\left.=195.89 \mu \mathrm{m}^{2} \quad\left(84.25-514.79 \mu \mathrm{m}^{2}\right)\right)$ and the $\mathrm{SNcv}$ (259.09 $\left.\mu \mathrm{m}^{2}\left(69.70-519.62 \mu \mathrm{m}^{2}\right)\right)$ when compared to the respective controls $\left(\mathrm{SNrm}\right.$, median $=246.43 \mu \mathrm{m}^{2}\left(86.35-496.17 \mu \mathrm{m}^{2}\right)$ and SNcv, median $\left.=292.475 \mu \mathrm{m}^{2}\left(109.28-527.454 \mu \mathrm{m}^{2}\right)\right)$ according to Kruskal-Wallis ANOVA Ranks test, followed by the Dunn's test, $P<0.01$ for both regions (Fig. $3 C$ ).

\subsection{Dietary EFA-deficiency over two generations decreases TH protein levels of ventral midbrain}

Quantitative analysis of TH levels in homogenates of the ventral midbrain showed a pronounced decline in the expression of this enzyme in the EF2 group when compared to control. Fig. 4 (panel A) shows the single band of $62 \mathrm{kDa}$ in both groups and Fig. 4 (panel
B) shows the $\mathrm{TH} /$ actin ratio and reveals a threefold difference between the groups.

\section{Discussion}

In the present study we investigated whether a long term treatment with a maternal diet containing reduced levels of both linoleic and $\alpha$-linolenic acids and high contents of saturated plus monounsaturated fatty acids could affect key components of midbrain dopaminergic system and two distinct dopaminergic cell populations of substantia nigra. The results demonstrated that this multigenerational model of EFA dietary restriction changed body and brain weights, $\mathrm{TH}$ protein levels in the ventral midbrain and the size of dopaminergic neurons. The number of these cells in the SNrm and SNcv were differentially affected.

\subsection{Repercussion of dietary treatment on body and brain weights}

The smaller body weight in the EF2 group is in agreement with previous studies using coconut oil as the only source of dietary lipids for one (Deuel et al., 1954; Soares et al., 1995) or two generations (Borba et al., 2010). Regarding this effect, it has been speculated that coconut oil can reduce body weight gain due to higher fatty acid turnover rates of the saturated medium chain fatty acids (8:0-14:0) which are oxidized more rapidly than long chain fatty acids (Hargrave et al., 2005). Moreover, this effect has also been associated with dysfunction of growth hormone regulation (Soares et al., 1995). A smaller EF2 group brain weight contrasts with previous studies adopting a dietary deficiency specific for $\alpha$-linolenic fatty acid for two or three generations, where no difference between the groups was detected either at 21 days (Ahmad et al., 2002a,b) or at adulthood (Ahmad et al., 2002b). Although distinct factors may be involved in brain and body weight 
A
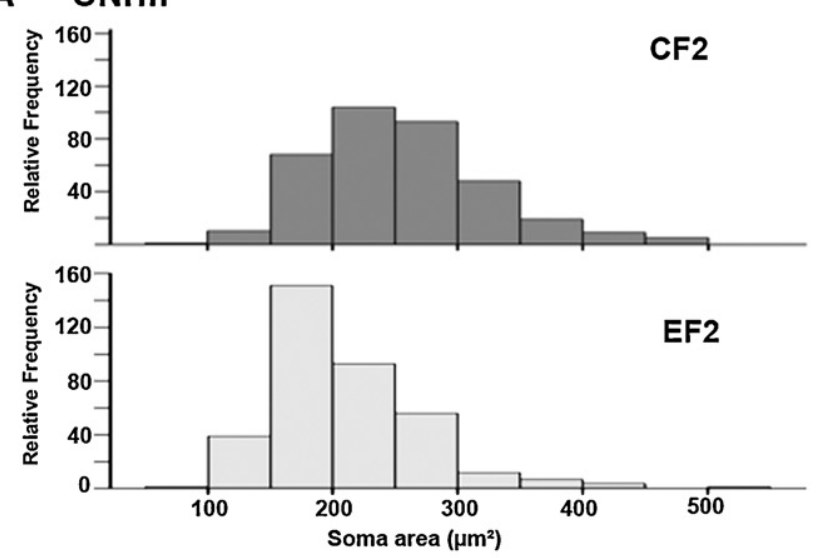

B
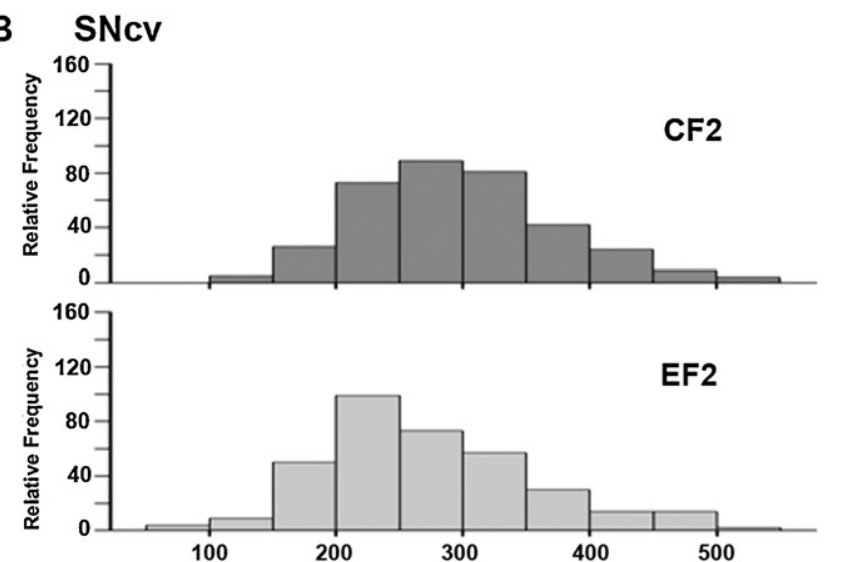

C

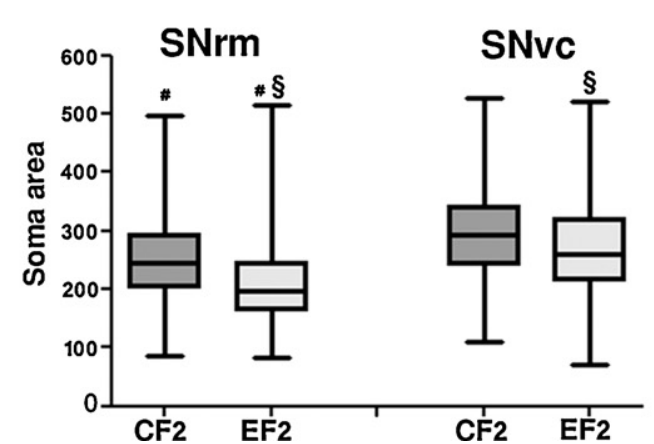

Fig. 3. EFA dietary restriction over two generations affects $\mathrm{SN}$ dopaminergic soma size. Comparative frequency histograms of dopaminergic cell soma size in the SNrm (A) and SNcv (B) of both groups show the predominant classes of soma size among the regions and groups ( $N=360$ cells per region). (C) The experimental condition resulted in lesser average soma size in both the SNrm $(\sim 20 \%)$ and SNcv $(\sim 10 \%)$ when compared to the control condition $(P<0.01$, Kruskal-Wallis test followed by the Dunn's test). \#, difference between regions; $\S$, difference between groups.

gains in the EF2 group, the modifications herein detected were similar in magnitude and did not change the brain/body weight ratio when compared to the control group. Taken together, these data show the effectiveness of the experimental diet in inducing systemic and localized developmental effects on the rat somatic growth.

\subsection{Midbrain fatty acid profile}

Previous second generation studies using balanced levels of saturated but a high linoleic/ $\alpha$-linolenic acid ratio $(\sim 134)$ have
A
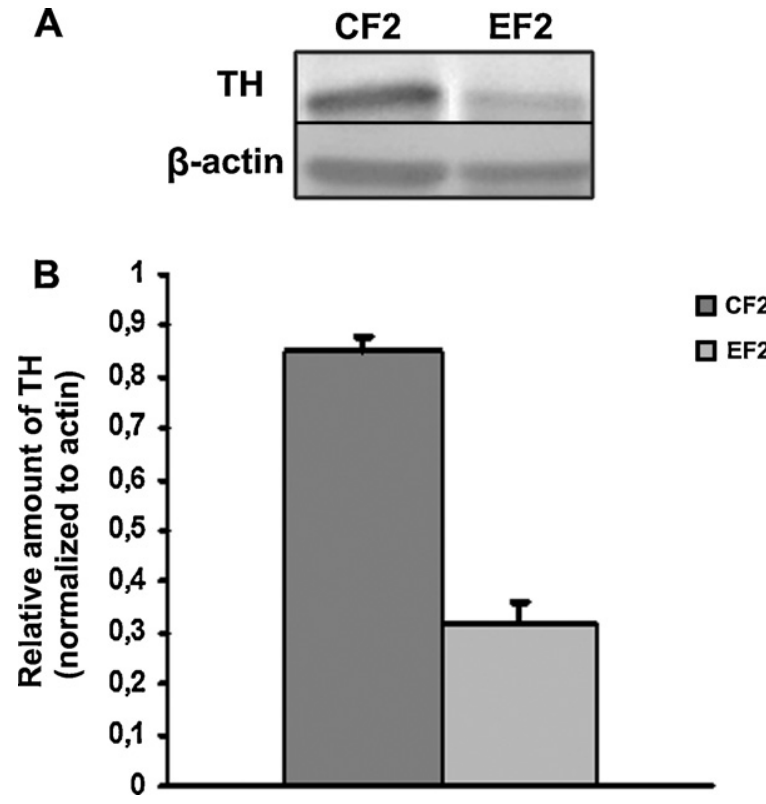

Fig. 4. Effect of EFA dietary restriction over two generations on $\mathrm{TH}$ protein levels in the ventral midbrain. Panel A shows the reduction in $\mathrm{TH}$-immunoreactive band of $62 \mathrm{kDa}$ as compared to $\beta$-actin ( $42 \mathrm{kDa}$ ). Panel B shows the TH/actin ratio and reveals a threefold difference between the groups. Values are expressed as arbitrary units normalized to $\beta$-actin and are average of six different animals of different dams.

shown distinct levels of DHA depletion among brain regions, with midbrain being less affected ( $\sim 64$ reduction) than the cerebral cortex and cerebellum ( $\sim 71 \%$ reduction) (Levant et al., 2006; Xiao et al., 2005). Recent evidence has indicated that a diet containing coconut oil as the only source of lipids can increase DHA depletion in the brain when compared to a fat free diet, even for a short term treatment (Ling et al., 2010). In the present study, the diet based on coconut oil and containing a linoleic/ $\alpha$-linolenic acid ratio of 16 resulted in lesser DHA levels ( $\sim 50 \%$ ) and increased the contents of some saturated and monounsaturated fatty acids in the midbrain phospholipids. The DHA deficiency was also confirmed by the compensatory increase in the DPA levels ( $\sim 6$ fold) which is an specific marker of $n-3$ fatty acid deficiency. Similar modification on the fatty acid profile was also observed in the cerebral cortex which indicates a widespread dietary impact on other brain regions. On the other hand, AA levels did not differ between the two groups, increasing the AA/DHA ratio in both regions analyzed. We suspect that at least three factors may have contributed to these results. First, the liver has a special ability to retain AA; and sustained AA levels in the young rat brain are consistent with up-regulated conversion from linoleic acid in the maternal, fetal and newborn liver (Satomi and Matsuda, 1973; Rapoport et al., 2007). Second, potential modifications in the transport of AA across the placenta can occur (Haggarty, 2002) and third, dietary $\alpha$-linolenic acid deficiency can upregulate the brain's expression of AA-selective metabolizing enzymes including cytosolic and secretory phospholipases A2 (Rao et al., 2007). Early and recent studies have also indicated that $\mathrm{AA}$ is more tightly controlled than DHA in the central nervous system and that its brain concentrations are less vulnerable to limitations in the supply of precursor than in other organs (Bourre et al., 1990; Brenna and Diau, 2007; Igarashi et al., 2009).

\subsection{Repercussion of dietary treatment on the number of dopaminergic cell populations}

Unbiased stereology demonstrated that the average total number of TH-positive cells in the SNrm of the EF2 young animals 
was $20 \%$ lower than the controls. This reduction is less than that reported for the entire SN pars compacta (33\%) of adult rats, associating successive parity and an $\alpha$-linolenic acid dietary deficiency (Ahmad et al., 2008). Despite the choice of the EFA deficiency experimental model, altogether, these data agree with the evidence of a protective action of DHA on subsets of SN dopaminergic neurons (Bousquet et al., 2008; Cansev et al., 2008) and seems to be consistent with previous data showing modifications in terminal fields of midbrain dopamine neurotransmission or dopamine-related behavior in $n-3$ deficient rats (Delion et al., 1996; Levant et al., 2004, 2010). Moreover, the increased AA/DHA ratio ( $\sim 2$ fold) in the midbrain phospholipids of EF2 group could also have an effect on the magnitude of the outcomes. An inverse relation between the number of some brain neurons and increasing ratios of $n-6 / n-3$ EFAs in the maternal diet has been recently reported (Tian et al., 2011). Imbalance in EFA levels, early in life, and especially $n$-3 LC-PUFA deficiency can lead to changes in brain metabolism, decreasing anti-inflammatory or anti-oxidative responses which can induce cellular suffering in different classes of neurons (Schmitz and Ecker, 2008; Innis, 2007). The increased AA/ DHA ratio in the EF2 group could enhance the effects of $n-6$ fatty acids via prostaglandin synthesis (Schmitz and Ecker, 2008; Rapoport et al., 2007). It has been demonstrated that the prostaglandin PGE2, a derivative of AA via cyclooxygenase-2 (COX-2), can induce neurotoxic effects on subpopulations of SN dopaminergic neurons in a dose and receptor-dependent manner (Carrasco et al., 2007). Furthermore, it has been also shown that dietary treatment with DHA caused a significant decrease in COX-2 activity and PGE2 levels in mice SN, reducing MPTP-induced dopaminergic cell death (Ozsoy et al., 2011).

A smaller average number of SNcv TH-immunoreactive cells in the EF2 group was observable, but no significant difference between the groups was detected, failing to confirm our initial hypothesis that such neurons could be more vulnerable than those of SNrm to the harmful effects of EFA dietary restriction. Although future studies will have to be carried out to determine mechanisms underlying the apparent resistance of these cells in our experimental model, one aspect is of immediate interest in the discussion of this data. Midbrain dopaminergic cell populations differ regarding the availability of some neurotrophins. For example, most dopaminergic neurons of ventral tegmental area (VTA) and SNrm, but not most those of SNcv, contain GDNF retrogradely transported from striatum (Barroso-Chinea et al., 2005). Recent evidence has indicated that DHA supplementation is able to increase GDNF and neurturin (NTN) levels in the SN, reduce dopaminergic cell death induced by MPTP (Tanriover et al., 2010) as well as increase brain-derived neurotrophic factor (BDNF) mRNA levels in the striatum (Bousquet et al., 2009). GDNF, NTN and BDNF in addition to other trophic factors can play differential and synergistic roles on developing SN dopaminergic neurons, maintaining their phenotypic profile and exerting cytoprotective effects (Akerud et al., 1999; Baquet et al., 2005; Stahl et al., 2011). However, dietary $n-3$ fatty acid deficiency for a short-term or over two generations is able to reduce mRNA and/or protein levels of BDNF in the rat cerebral cortex (Rapoport et al., 2007; Rao et al., 2007) and mouse striatum (Miyazawa et al., 2010). Considering that the repercussion of LC-PUFA deficiency on the levels of some neurotrophins can differ among brain regions (Miyazawa et al., 2010), thus leads us to speculate that the differential effects on dopaminergic cell number in SNrm and SNcv could involve a distinct sensitivity of these cell populations to potential modifications on neurotrophin-related mechanisms. With respect to this, $n$ 3 EFA deficiency could impair compensatory mechanisms that usually confer less vulnerability to degeneration in some midbrain dopaminergic cells. Adopting a bidimensional analysis we also detected fewer dopaminergic neurons at the middle level of VTA in the EF2 group (Supplementary Fig. 1). Such results are qualitatively similar to that described by Ahmad et al. (2008) using stereology. Likewise the SNrm, the VTA region usually displays highest resistance to degeneration when compared to SNcv (BarrosoChinea et al., 2005).

\subsection{Repercussion of dietary treatment on dopaminergic cell size}

The lower values of soma area observed in both SN dopaminergic cell populations of the EF2 group seems to be qualitatively similar to previous data on neurons of the hippocampus, hypothalamus, and both piriform and parietal cortices in multigenerational models of $\alpha$-linolenic deficiency (Ahmad et al., 2002a,b). These previous studies did not identify the neurotransmitter phenotypes and showed that reduction in neuron size in the DHA-deficient diet group was greater in rats at weaning age (21 days) compared to older ones (68 days) in most brain regions, except in the piriform cortex (Ahmad et al., 2002a). In the CA1 region of hippocampus, for example, $n-3$ deficient diet induced lesser size of neurons without altering other parameters including total number of neurons (Ahmad et al., 2002b). The present data on SN dopaminergic cells of the EF2 group at 30-42 days differs from those reported in the SNpc of Long Evans rats at 70 days (Ahmad et al., 2008) where no difference on soma volume was detected between the control and $n-3$ deficient groups. Although methodological issues and age of animals may have contributed to the observed differences, the present findings reinforce previous evidence that DHA levels can affect the growth and development of neurons and suggest that this effect may not be specifically restricted to a particular neurochemical profile or brain region. With regard to this, it is noteworthy to consider that in the developing brain, DHA is a ligand for the retinoid X-receptor (Lengqvist et al., 2004), which plays a major role in the morphological differentiation of dopaminergic neurons (Castro et al., 2001).

\subsection{TH protein levels in the ventral midbrain}

Western blotting analysis in ventral midbrain of the EF2 group shows a lower TH protein levels when compared to the controls. Taking into account that our samples contain other TH-immunoreactive nuclei adjacent to $\mathrm{SN}$, these results show a diffused effect of EFA dietary restriction on midbrain dopaminergic systems. They are also consistent with the reduced $\mathrm{TH}$-immunoreactivity pattern and number of $\mathrm{TH}$-immunoreactive neurons herein detected in the $\mathrm{SN}$. A recent study using a diet containing ten times higher linoleic to $\alpha$-linolenic acid ratio $(\sim 178)$ than the ratio presented in our experimental diet, reported a time-dependent decline in the $\mathrm{TH}$ levels of SN in lactant pups of the first generation (Kuperstein et al., 2008). The present work using a two-generation dietary treatment reinforces the sensitivity of this rate-limiting enzyme in the biosynthesis of dopamine to unbalanced levels of fatty acids, indicating a long-lasting, non-compensated effect on the ventral midbrain.

\section{Conclusion}

Our results demonstrate for the first time a differential sensitivity of two functionally distinct SN dopaminergic cell populations to unbalanced dietary levels of EFA. Considering that under physiological conditions SNrm is usually more resistant than SNcv to other different kinds of insults, the present results suggest that EFA dietary restriction during brain development, could impair homeostatic mechanisms, modifying the degeneration profile of dopaminergic cells under a variety of pathological conditions. In this respect, the current findings seem to be in 
agreement with a recent prospective study in humans, that has positively associated a high intake of PUFA, specifically $n-3$ PUFA, with a lower risk of developing Parkinson disease (de Lau et al., 2005).

\section{Conflict of interest}

There is no conflict of interest in the work reported in the present paper.

\section{Acknowledgments}

The authors are grateful to Zenira.Cosme Xavier and Mauricéia A. Silva for technical assistance and to John David Bousfield and Sidney Pratt for helpful comments and reviewing the English version of the text. The acquisition of the reagents used in this work was supported by the financial support from the Brazilian National Research Council (CNPq; Projeto Casadinho \# 620248/2004-1); CAPES (PROCAD \# 0008052/2006 and PROCAD NF-2010), FINEP/ IBN-Net. (\# 01.06.0842-00) and MCT-CNPq/MS-SCTIE-DECIT (no. 17/2006). R.C.A. Guedes is Research fellow of CNPq (\# 302565/ 2007-8).

\section{Appendix A. Supplementary data}

Supplementary data associated with this article can be found, in the online version, at http://dx.doi.org/10.1016/j.jchemneu.2012.05.003.

\section{References}

Ahmad, A., Moriguchi, T., Salem, N., 2002a. Decrease in neuron size in docosahexaenoic acid-deficient brain. Pediatric Neurology 26, 210-218, http://dx.doi.org/ 10.1016/S0887-8994(01)00383-6.

Ahmad, A., Murthy, M., Greiner, R.S., Moriguchi, T., Salem Jr., N., 2002b. A decrease in cell size accompanies a loss of docosahexaenoate in the rat hippocampus. Nutritional Neuroscience 5, 103-113.

Ahmad, S.O., Park, J.H., Radel, J.D., Levant, B., 2008. Reduced numbers of dopamine neurons in the substantia nigra pars compacta and ventral tegmental area of rats fed an $n-3$ polyunsaturated fatty acid-deficient diet: a stereological study. Neuroscience Letters 438, 303-307, http://dx.doi.org/10.1016/j.neulet.2008.04.073.

Akerud, P., Alberch, J., Eketjäll, S., Wagner, J., Arenas, E., 1999. Differential effects of glial cell line-derived neurotrophic factor and neurturin on developing and adult substantia nigra dopaminergic neurons. Journal of Neurochemistry 73 , 70-78, http://dx.doi.org/10.1046/j.1471-4159.1999.0730070.x.

Baquet, Z.C., Bickford, P.C., Jones, K.R., 2005. Brain-derived neurotrophic factor is required for the establishment of the proper number of dopaminergic neurons in the substantia nigra pars compacta. Journal of Neuroscience 25, 6251-6259, http://dx.doi.org/10.1523/JNEUROSCI.4601-04.2005.

Barroso-Chinea, P., Cruz-Muros, I., Aymerich, M.S., Rodríguez-Díaz, M., AfonsoOramas, D., 2005. Striatal expression of GDNF and differential vulnerability of midbrain dopaminergic cells. European Journal of Neuroscience 7, 18151827, http://dx.doi.org/10.1111/j.1460-9568.2005.04024.x.

Bayer, S.A., Wills, K.V., Triarhou, L.C., Ghetti, B., 1995. Time of neuron origin and gradients of neurogenesis in midbrain dopaminergic neurons in the mouse. Experimental Brain Research 105, 191-199.

Berry, J.F., Cevallos, W.H., Wade, R.R., 1965. Lipid class and fatty acid composition of intact peripheral nerve and during Wallerian degeneration. Journal of the American Oil Chemists Society 42, 492-500.

Borba, J.M.C., Rocha-de-Melo, A.P., Amâncio dos Santos, A., Andrade da Costa, B.L.S Silva, R.P., 2010. Essential fatty acid deficiency reduces cortical spreading depression propagation in rats: a two-generation study. Nutritional Neuroscience 13, 144-150, http://dx.doi.org/10.1179/147683010X12611460763887.

Bourre, J.M., Piciotti, M., Dumont, O., Pascal, G., Durand, G., 1990. Dietary linoleic acid and polyunsaturated fatty acids in rat brain and other organs: minimal requirements of linoleic acid. Lipids 25, 465-472.

Bousquet, M., Gibrat, C., Saint-Pierre, M., Julien, C., Calon, F., 2009. Modulation of brain-derived neurotrophic factor as a potential neuroprotective mechanism of action of omega-3 fatty acids in a Parkinsonian animal model. Progress in Neuro-Psychopharmacology and Biological Psychiatry 33, 1401-1408, http:// dx.doi.org/10.1016/j.pnpbp.2009.07.018.

Bousquet, M., Saint-Pierre, M., Julien, C., Salem Jr., N., Cicchetti, F., 2008. Beneficial effects of dietary omega-3 polyunsaturated fatty acid on toxin-induced neuro- nal degeneration in an animal model of Parkinson's disease. FASEB Journal 22, 1213-1225, http://dx.doi.org/10.1096/fj.07-9677com.

Brenna, J.T., Diau, G.Y., 2007. The influence of dietary docosahexaenoic acid and arachidonic acid on central nervous system polyunsaturated fatty acid composition. Prostaglandins Leukotrienes and Essential Fatty Acids 77, 247-250, http://dx.doi.org/10.1016/j.plefa.2007.10.016.

Cansev, M., Ulus, I.H., Wang, L., Maher, T.J., Wurtman, R.J., 2008. Restorative effects of uridine plus docosahexaenoic acid in a rat model of Parkinson's disease. Neuroscience Research 62, 206-209, http://dx.doi.org/10.1016/j.neures. 2008.07.005

Carrasco, E., Casper, D., Werner, P., 2007. PGE(2) receptor EP1 renders dopaminergic neurons selectively vulnerable to low-level oxidative stress and direct PGE(2) neurotoxicity. Journal of Neuroscience Research 85, 3109-3117 10.1002 jnr.21425.

Castro, D.S., Hermanson, E., Joseph, B., Wallén, A., Aarnisalo, P., 2001. Induction of cell cycle arrest and morphological differentiation by Nurr1 and retinoids in dopamine MN9D cells. Biological Chemistry 276 (46), 43277-43284, http:// dx.doi.org/10.1074/jbc.M107013200.

Chalon, S., 2006. Omega-3 fatty acids and monoamine neurotransmission. Prostaglandins Leukotrienes and Essential Fatty Acids 75 (4-5), 259-269, http:// dx.doi.org/10.1016/j.plefa.2006.07.005

Damier, P., Hirsch, E.C., Agid, Y., Graybiel, A.M., 1999. The substantia nigra of the human brain. II. Patterns of loss of dopamine-containing neurons in Parkinson's disease. Brain 122, 1437-1448, http://dx.doi.org/10.1093/brain/122.8.1437.

de Lau, L.M., Bornebroek, M., Witteman, J.C., Hofman, A., Koudstaal, P.J., 2005 Dietary fatty acids and the risk of Parkinson disease: the Rotterdam study. Neurology 64, 2040-2045.

Delion, S., Chalon, S., Guilloteau, D., Besnard, J.C., Durand, G., 1996. Alpha-linolenic acid dietary deficiency alters age-related changes of dopaminergic and serotoninergic neurotransmission in the rat frontal cortex. Journal of Neurochemistry 66, 1582-1591.

Deuel, H.J., Alfin-Slater Jb, E.B., Wells, A.F., Krydeh, G.D., Aftergood, L., 1954. The effect of fat level of the diet on general nutrition. XIV. Further studies of the effect of hydrogenated coconut oil on essential fatty acid deficiency in the Ra. Journal of Nutrition 55, 337-346.

Duke, D.C., Moran, L.B., Pearce, R.K., Graeber, M.B., 2007. The medial and lateral substantia nigra in Parkinson's disease: mRNA profiles associated with higher brain tissue vulnerability. Neurogenetics 8, 83-94, http://dx.doi.org/10.1007| s10048-006-0077-6.

Fedorova, I., Alvheim, A.R., Hussein, N., Salem Jr., N., 2009. Deficit in prepulse inhibition in mice caused by dietary $n-3$ fatty acid deficiency. Behavioral Neuroscience 123, 1218-1225, http://dx.doi.org/10.1037/a0017446.

Folch, J., Lees, M., Sloane Stanley, G.H., 1957. A simple method for the isolation and purification of total lipids from animal tissues. Journal of Biological Chemistry 226, 497-509.

Gaspar, P., Ben Jelloun, N., Febvret, A., 1994. Sparing of the dopaminergic neurons containing calbindin-D28k and of the dopaminergic mesocortical projections in weaver mutant mice. Neuroscience 61, 293-305, http://dx.doi.org/10.1016/ 0306-4522(94)90232-1.

Glaser, E.M., Wilson, P.D., 1998. The coefficient of error of optical fractionator population size estimates: a computer simulation comparing three estimators. Journal of Microscopy 192 (Pt 2), 163-171, http://dx.doi.org/10.1046/j.13652818.1998.00417.x.

González-Hernández, T., Barroso-Chinea, P., De La Cruz Muros, I., Del Mar PérezDelgado, M., Rodríguez, M., 2004. Expression of dopamine and vesicular monoamine transporters and differential vulnerability of mesostriatal dopaminergic neurons. Journal of Comparative Neurology 479, 198-215, http://dx.doi.org/ $10.1002 /$ cne. 20323.

Haggarty, P., 2002. Placental regulation of fatty acid delivery and its effect on fetal growth-a review. Placenta 23, S28-S38, http://dx.doi.org/10.1053 plac.2002.0791.

Hargrave, K.M., Azain, M.J., Miner, J.L., 2005. Dietary coconut oil increases conjugated linoleic acid-induced body fat loss in mice independent of essential fatty acid deficiency. Biochimica et Biophysica Acta 1737, 52-60, http://dx.doi.org/ 10.1016/j.bbalip.2005.08.016.

Hartman, L., Lago, R.C.A., 1973. Rapid preparation of fatty acid methyl ester from lipids. Laboratory Practice 22, 475-476.

Heinrichs, S.C., 2010. Dietary omega-3 fatty acid supplementation for optimizing neuronal structure and function. Molecular Nutrition \& Food Research 54, 447456, http://dx.doi.org/10.1002/mnfr.200900201.

Igarashi, M., Gao, F., Kim, H.W., Ma, K., Bell, J.M., Rapoport, S.I., 2009. Dietary n-6 PUFA deprivation for 15 weeks reduces arachidonic acid concentrations while increasing $n-3$ PUFA concentrations in organs of post-weaning male rats. Biochimica et Biophysica Acta 1791, 132-139, http://dx.doi.org/10.1016/j.bbalip.2008.11.002.

Innis, S.M., 2007. Fatty acids and early human development. Early Human Development 83, 761-766, http://dx.doi.org/10.1016/j.earlhumdev.2007.09.004.

Joel, D., Weiner, I., 2000. The connections of the dopaminergic system with the striatum in rats and primates: an analysis with respect to the functional and compartmental organization of the striatum. Neuroscience 96, 451-474, http:/| dx.doi.org/10.1016/S0306-4522(99)00575-8.

Juaneda, P., Rocquelin, G., 1985. Rapid and convenient separation of phospholipids and nonphosphorus lipids from rat heart using silica cartridges. Lipids 20 , 40-41.

Kim, S.J., Zhang, Z., Saha, A., Sarkar, C., Zhao, Z., 2010. Omega-3 and omega-6 fatty acids suppress ER- and oxidative stress in cultured neurons and neuronal 
progenitor cells from mice lacking PPT1. Neuroscience Letters 479, 292-296, http://dx.doi.org/10.1016/j.neulet.2010.05.083.

Kuperstein, F., Eilam, R., Yavin, E., 2008. Altered expression of key dopaminergic regulatory proteins in the postnatal brain following perinatal $n-3$ fatty acid dietary deficiency. Journal of Neurochemistry 106, 662-671 10.1111/j.14714159.2008.05418.x.

Lang-Lazdunski, L., Blondeau, N., Jarretou, G., Lazdunski, M., Heruteaux, C., 2003. Linolenic acid prevents neuronal cell death and paraplegia after transient spina cord ischemia in rats. Journal of Vascular Surgery 38, 564-575, http:// dx.doi.org/10.1016/S0741-5214(03)00473-7.

Lengqvist, J., Mata de Urquiza, A., Bergman, A.C., Willson, T.M., Sjovall, J., 2004 Polyunsaturated fatty acids including docosahexaenoic and arachidonic acid bind to the retinoid $\mathrm{X}$ receptor alpha ligand-binding domain. Molecular and Cellular Proteomics 3, 692-703, http://dx.doi.org/10.1074/mcp.M400003MCP200.

Levant, B., Radel, J.D., Carlson, S.E., 2004. Decreased brain docosahexaenoic acid during development alters dopamine-related behaviors in adult rats that are differentially affected by dietary remediation. Behavioural Brain Research 152 49-57.

Levant, B., Ozias, M.K., Jones, K.A., Carlson, S.E., 2006. Differential effects of modulation of docosahexaenoic acid content during development in specific regions of rat brain. Lipids 41, 407-414.

Levant, B., Zarcone, T.J., Fowler, S.C., 2010. Developmental effects of dietary $n$ - 3 fatty acids on activity and response to novelty. Physiology and Behavior 101, 176183.

Ling, P.R., De Leon, C.E., Le, H., Puder, M., Bistrian, B.R., 2010. Early development of essential fatty acid deficiency in rats: fat-free vs. hydrogenated coconut oil diet. Prostaglandins Leukotrienes and Essential Fatty Acids 83, 229-237, http:// dx.doi.org/10.1016/j.plefa.2010.07.004.

McNamara, R.K., Carlson, S.E., 2006. Role of omega-3 fatty acids in brain development and function: potential implications for the pathogenesis and prevention of psychopathology. Prostaglandins Leukotrienes and Essential Fatty Acids 75, 329-349, http://dx.doi.org/10.1016/j.plefa.2006.07.010.

Medina, J.M., Tabernero, A., 2002. Astrocyte-synthesized oleic acid behaves as a neurotrophic factor for neurons. Journal of Physiology, Paris 96, 265-271, http://dx.doi.org/10.1016/S0928-4257(02)00015-3.

Miyazawa, D., Yasui, Y., Yamada, K., Ohara, N., Okuyama, H., 2010. Regiona differences of the mouse brain in response to an $\alpha$-linolenic acid-restricted diet: neurotrophin content and protein kinase activity. Life Sciences 87, 490 494, http://dx.doi.org/10.1016/j.lfs.2010.09.003.

Ozsoy, O., Tanriover, G., Derin, N., Uysal, N., Demir, N., 2011. The effect of docosahexaenoic acid on visual evoked potentials in a mouse model of Parkinson's disease: the role of cyclooxygenase-2 and nuclear factor kappa-B. Neurotoxicity Research 20, 250-262, http://dx.doi.org/10.1007/s12640-011-9238-y.

Paxinos, G., Watson, C., 1986. The Rat Brain in Stereotaxic Coordinates, 2nd edition. Academic Press Inc., California.

Polo-Hernández, E., De Castro, F., García-García, A.G., Tabernero, A., Medina, J.M. 2010. Oleic acid synthesized in the periventricular zone promotes axonogenesis in the striatum during brain development. Journal of Neurochemistry 114 , 1756-1766, http://dx.doi.org/10.1111/j.1471-4159.2010.06891.x.

Prensa, L., Parent, A., 2001. The nigrostriatal pathway in the rat: a single-axon study of the relationship between dorsal and ventral tier nigral neurons and the striosome/matrix striatal compartments. Journal of Neuroscience 21, 7247 7260.

Rao, J.S., Ertley, R.N., DeMar Jr., J.C., Rapoport, S.I., Bazinet, R.P., 2007. Dietary n-3 PUFA deprivation alters expression of enzymes of the arachidonic and docosahexaenoic acid cascades in rat frontal cortex. Molecular Psychiatry 12, 151157, http://dx.doi.org/10.1038/sj.mp.4001887.

Rapoport, S.I., Rao, J.S., Igarashi, M., 2007. Brain metabolism of nutritionally essential polyunsaturated fatty acids depends on both the diet and the liver. Prostaglandins Leukotrienes and Essential Fatty Acids 77, 251-261, http:// dx.doi.org/10.1016/j.plefa.2007.10.023.
Robson, L.G., Dyall, S., Sidloff, D., Michael-Titus, A.T., 2010. Omega-3 polyunsaturated fatty acids increase the neurite outgrowth of rat sensory neurons throughout development and in aged animals. Neurobiology of Aging 31, 678-687, http://dx.doi.org/10.1016/j.neurobiolaging.2008.05.027.

Rodríguez, M., Barroso-Chinea, P., Abdala, P., Obeso, J., González-Hernández, T. 2001. Dopamine cell degeneration induced by intraventricular administration of 6-hydroxydopamine in the rat: similarities with cell loss in Parkinson's disease. Experimental Neurology 169, 163-181, http://dx.doi.org/10.1006/ exnr.2000.7624.

Satomi, S., Matsuda, I., 1973. Microsomal desaturation of linoleic into $\gamma$-linolenic acid in livers of fetal, suckling and pregnant rats. Biology of the Neonate 22, 1-8.

Schmitz, G., Ecker, J., 2008. The opposing effects of $n-3$ and $n-6$ fatty acids. Progress in Lipid Research 47, 147-155, http://dx.doi.org/10.1016/j.plipres.2007.12.004.

Soares, M.C., Aléssio, M.L., Léger, C.L., Bluet-Pajot, M.T., Clauser, H., 1995. Effect of essential fatty acid deficiency on membrane fatty acid content and growth hormone stimulation of rat pituitaries during postnatal development. Journal of Lipid Research 36, 1401-1406.

Stahl, K., Mylonakou, M.N., Skare, O., Amiry-Moghaddam, M., Torp, R., 2011. Cytoprotective effects of growth factors: BDNF more potent than GDNF in an organotypic culture model of Parkinson's disease. Brain Research 1378, 105118, http://dx.doi.org/10.1016/j.brainres.2010.12.090.

Tanriover, G., Seval-Celik, Y., Ozsoy, O., Akkoyunlu, G., Savcioglu, F., 2010. The effects of docosahexaenoic acid on glial derived neurotrophic factor and neurturin in bilateral rat model of Parkinson's disease. Folia Histochemica et Cytobiologica 48, 434-441, http://dx.doi.org/10.2478/v10042-010-0047-6.

Tian, C., Fan, C., Liu, X., Xu, F., Qi, K., 2011. Brain histological changes in young mice submitted to diets with different ratios of $n-6 / n-3$ polyunsaturated fatty acids during maternal pregnancy and lactation. Clinical Nutrition 30, 659-667, http://dx.doi.org/10.1016/j.clnu.2011.03.002.

Towbin, H., Staehelin, T., Gordon, J., 1979. Electrophoretic transfer of proteins from polyacrylamide gels to nitrocellulose sheets: procedure and some applications. Proceedings of the National Academy of Sciences of the United States of America $76,4350-4354$.

Uauy, R., Dangour, A.D., 2006. Nutrition in brain development and aging: role of essential fatty acids. Nutrition Reviews 64, S24-S33, http://dx.doi.org/10.1111/ j.1753-4887.2006.tb00242.x (discussion S72-S91).

Uhl, G.R., Walther, D., Mash, D., Faucheux, B., Javoy-Agid, F., 1994. Dopamine transporter messenger RNA in Parkinson's disease and control substantia nigra neurons. Annals of Neurology 35, 494-498.

Vines, A., Delattre, A.M., Lima, M.M., Rodrigues, L.S., Suchecki, D., Machado, R.B. Tufik, S., Pereira, S.I., Zanata, S.M., Ferraz, A.C., 2012. The role of 5-HT receptors in fish oil-mediated increased BDNF expression in the rat hippocampus and cortex: a possible antidepressant mechanism. Neuropharmacology 62, 184-191.

Wang, Z.J., Liang, C.L., Li, G.M., Yu, C.Y., Yin, M., 2007. Stearic acid protects primary cultured cortical neurons against oxidative stress. Acta Pharmacologica Sinica 28, 315-326, http://dx.doi.org/10.1111/j.1745-7254.2007.00512.x.

West, M.J., 2002. Design-based stereological methods for counting neurons. Progress in Brain Research 135, 43-51, http://dx.doi.org/10.1016/S00796123(02)35006-4

Xiao, Y., Yu, H., Zyu, C., 2005. Distribution, depletion and recovery of docosahexaenoic acid are region-specific in rat brain. British Journal of Nutrition 94, 544550, http://dx.doi.org/10.1079/BJN20051539.

Yamada, T., McGeer, P.L., Baimbridge, K.G., McGeer, E.G., 1990. Relative sparing in Parkinson's disease of substantia nigra dopamine neurons containing calbindin-D28K. Brain Research 526, 303-307.

Yavin, E., 2006. Docosahexaenoic acid: a pluripotent molecule acting as a membrane fluidizer, a cellular anti-oxidant and a modulator of gene expression. Nutrition and Health 18, 261-262.

Zimmer, L., Delpal, S., Guilloteau, D., Aïoun, J., Durand, G., Chalon, S., 2000. Chronic $n-3$ polyunsaturated fatty acid deficiency alters dopamine vesicle density in the rat frontal cortex. Neuroscience Letters 284, 25-28. 